\title{
Prevalence of Allergies among University Students: A Study from Ajman, United Arab Emirates
}

\section{Lisha Jenny John, ${ }^{1}$ Sharfaa Ahmed, ${ }^{2}$ Fiza Anjum, ${ }^{2}$ Mohieddin Kebab, ${ }^{2}$ Naik Mohammed, ${ }^{2}$ Haitham Darwich, ${ }^{2}$ Nusaibah Ibraheem, ${ }^{2}$ Mohamed Arifulla, ${ }^{1}$ and Jayadevan Sreedharan ${ }^{3}$}

${ }^{1}$ Department of Pharmacology, Gulf Medical University, Ajman 4184, UAE

${ }^{2}$ College of Medicine, Gulf Medical University, Ajman 4184, UAE

${ }^{3}$ Statistical Support Facility, CABRI, Gulf Medical University, Ajman 4184, UAE

Correspondence should be addressed to Lisha Jenny John; drlishaj@yahoo.com

Received 11 November 2013; Accepted 2 January 2014; Published 19 February 2014

Academic Editors: S. Burastero and G. Riccioni

Copyright (C) 2014 Lisha Jenny John et al. This is an open access article distributed under the Creative Commons Attribution License, which permits unrestricted use, distribution, and reproduction in any medium, provided the original work is properly cited.

\begin{abstract}
Aim. Urbanization and globalization in the Middle East have resulted in drastic environmental changes and increased allergens present in the environment. This study aimed to assess the prevalence of allergies among undergraduate students from a university. Material and Methods. This cross-sectional survey was carried out among undergraduate students of a University at Ajman, UAE. A self-administered questionnaire was used as research instrument for data collection. The demographic data and the allergy characteristics were collected and analyzed using SPSS version 19. Descriptive and inferential statistics were performed. Results. A total of 255 students (33.3\% males; $66.7 \%$ females) were included. Commonest allergies among the students were allergic conjunctivitis (104 (40.8\%)), allergic dermatitis (89 (34.9\%)), and eczema (38 (14.9\%)). Family history of allergies was strongly associated with occurrence of allergic conjunctivitis and allergic dermatitis. In about $58(22 \%)$ of the students, dust was the most common triggering factor for allergies. Allergies associated with pollen, food, and drugs were less frequent. The distribution of allergies based on gender revealed female preponderance in all types of allergies. Students with allergies reported interference with their daily activities, and academic, social, and extracurricular activities. Conclusions. Allergic conjunctivitis and allergic dermatitis were the frequent allergies reported. Adequate preventive strategies can crumb the prevalence of allergies.
\end{abstract}

\section{Introduction}

Atopic diseases have a wide range of manifestations across the globe, imposing heavy social and economic burden due to their chronicity and effects on various functions of the body [1]. Allergies during college years impact the quality of life by interfering with the daily activities, poor attendance to college, sleep disturbances, and inability to perform academical as well as extracurricular activities. Studies have also documented that allergies are more common in the urban and industrialized societies than the less industrialized regions [2]. Von Hertzen and Haahtela from Finland, reported an increase in the occurrence of allergies among individuals living in the city [3]. Previous studies carried out in the UAE revealed a prevalence rate of $7.3 \%$ of asthma and allergic rhinitis and were caused mainly by pollen, mould spores, and dust mite allergens in the air. Prevalence of food allergy among children in UAE is $8 \%$ with a significant association with family history [4].

The risk factors attributed to the increasing prevalence of allergies among the Gulf countries include globalization resulting in substantial environmental changes such as increased exposure to pollen due to antidesertification projects and genetic factors may also contribute to the prevalence in certain ethnic groups [5]. Epidemiological studies from the Gulf region on allergic disorders have shown significant discrepancies in the prevalence of asthma and other allergic disorders as well as variations in the possible risk factors [6-8].

On determining the prevalence of allergies among students and any association between gender, ethnic groups and length of stay in the region with the allergies would provide 
useful information to suggest strategies among students to modification and suggestions to improve their health. Hence, this study aimed to assess the prevalence of allergies among undergraduate students of a University at Ajman, UAE.

\section{Material and Methods}

This cross-sectional survey was carried out over a period of 6 months (September 2011-February 2012) among undergraduate students of the four colleges of the University. Approval for the study was obtained from the Ethics Committee for conducting this study. All students willing to participate in the study were included. Students who were not willing to participate and those not present during the administration of questionnaire were excluded from the study. Data collection was performed using a self-administered pilot-tested questionnaire with the following domains: sociodemographic characteristics (age, gender, nationality, and length of stay in UAE), allergy characteristics, and family history of allergies. Copies of the questionnaire were handed out to the students during their break.

Descriptive analysis was performed on the data collected using SPSS version 19. Chi- square test was used to test for any association between allergies and variables such as age, gender, nationality, length of stay, and quality of life.

\section{Results}

A total of 255 students (85 (33.3\%) males and 170 (66.7\%) females) were included. The mean age was $20 \pm 2.6$ years. The mean duration of stay in the UAE was about $104.9 \pm 90.4$ months; the frequency varies from one month to 312 months. The characteristics of the study population are shown in Table 1.

The common allergies self-reported by the students included allergic conjunctivitis 104 (40.8\%), allergic dermatitis 89 (34.9\%), and eczema 38 (14.9\%). The self-reported allergic disorders (single and combination) among the students have been illustrated in Figure 1. Only 54 (21.1\%) students reported single allergic disorders. Allergic conjunctivitis and rhinitis were coexistent in 53 students (20.7\%) and combination of allergic dermatitis and rhinitis was coexistent in $40(15.7 \%)$ students. Among those students with a family history of allergic dermatitis, 35 (56.5\%) of them had allergic dermatitis $(P<0.001)$; those students were reporting positive family history of allergic conjunctivitis and $22(68.8 \%)$ of them had allergic conjunctivitis $(P<0.001)$. Most of the students noted that their allergies were common during spring season of the year (March-May).

The details of gender-based distribution of allergies are detailed in Table 2. A female preponderance was observed in all the types of allergies. There was no association between the type of allergies and length of stay in the UAE or between the allergies and the nationality of students.

Interference with their daily activities, academic activities, and social and extracurricular activities was reported by students with allergies. Allergic conjunctivitis interfered with daily activities, social and extracurricular activities,
TABLE 1: Sociodemographic characteristics of university students.

\begin{tabular}{lccc}
\hline Characteristic & Item & Number & Percentage \\
\hline \multirow{2}{*}{ Gender } & Male & 85 & 33.3 \\
Age & Female & 170 & 66.7 \\
Course & Mean \pm standard deviation & $20.1 \pm 2.58$ years \\
& Medicine & 150 & 58.8 \\
& Dentistry & 59 & 23.1 \\
& Pharmacy & 10 & 3.9 \\
Length of stay & Physical therapy & 36 & 14.1 \\
& <1 year & 39 & 15.3 \\
& 1-5 years & 61 & 23.9 \\
& 5-10 years & 37 & 14.5 \\
& 10-15 years & 23 & 9.0 \\
& 215 years & 95 & 37.3 \\
& India & 37 & 14.5 \\
& Pakistan & 38 & 14.9 \\
Nationality & Other Asians & 12 & 4.7 \\
& Africa & 36 & 14.1 \\
& United Arab Emirates & 31 & 12.2 \\
& Other Middle Easterns & 54 & 21.2 \\
& Europe & 10 & 3.9 \\
& Others & 37 & 14.5 \\
\hline
\end{tabular}

academic performance, and college attendance in 32 (45.1\%), 25 (35.7\%), 13 (19.4\%), and 11 (16.9\%) students, respectively. Allergic dermatitis interfered with daily activities in social and extracurricular activities, academic performance, and college attendance in 28 (46.7\%), 9 (29.8\%), 11 (19.6\%), and $7(13.5 \%)$ students correspondingly. Allergic conjunctivitis and allergic dermatitis and their interference with the daily activities were found to be statistically significant $(P<0.01)$.

Dust was the most common trigger for all the allergies (58 (22\%)) (allergic rhinitis, conjunctivitis, dermatitis, and eczema) among the students. The most common food allergies were associated with sea food and nuts. Drug allergies were reported by 18 (7\%) students, most frequently to antibiotics, especially the penicillin group of drugs.

\section{Discussion}

United Arab Emirates, as a country, has been through a major transition shifting from traditional to a modern society with urbanization, industrialization, and associated environmental changes resulting in an increase in the allergens present in the environment and the prevalence of allergies. In our study sample, the female students were predominant, with a majority of the students being below 20 years of age.

Dust was the most common trigger for all the allergies (allergic rhinitis, conjunctivitis dermatitis, and eczema). These results indicate that dust plays an important role in worsening allergic symptoms, as has been reported earlier by Bener et al. [9]. Urbanization has changed the home settings immensely with the introduction of soft furnishings, fitted carpets, central cooling, and decreased indoor ventilation which lead to a considerable increase in indoor pollutants 


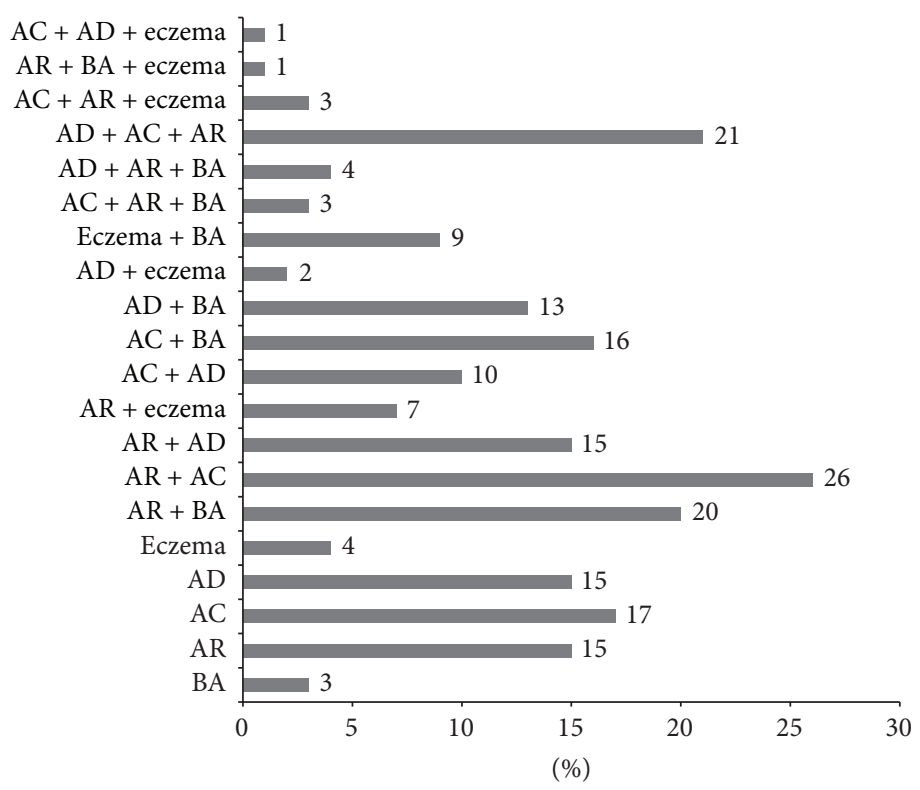

FIGURE 1: Distribution of allergic disorders among the university students. BA: bronchial asthma; AR: allergic rhinitis; AC: allergic conjunctivitis; AD: allergic dermatitis.

TABLE 2: Gender-based distribution of allergic disorders among university students.

\begin{tabular}{lcccc}
\hline Allergies & Male & Female & Total & $P$ value \\
\hline Allergic conjunctivitis & $25(24 \%)$ & $79(76 \%)$ & 104 & 8.05 \\
Allergic dermatitis & $21(23.5 \%)$ & $66(76.5 \%)$ & NS \\
Eczema & $12(31.5 \%)$ & $26(68.5 \%)$ & 38 & NS \\
Dust allergies & $18(31 \%)$ & $40(69 \%)$ & 58 & NS \\
Food allergies & $6(25 \%)$ & $18(75 \%)$ & 24 & NS \\
Drug allergies & $6(33.3 \%)$ & $12(66.7 \%)$ & 18 & NS \\
Pollen allergies & $4(30.7 \%)$ & $9(69.3 \%)$ & NS \\
\hline
\end{tabular}

and airborne allergens. As noted in this study the allergies were common during spring and the probable trigger is being pollen and dust mites. Similar observation was noted by another study from the United Arab Emirates [10]. Health education should be imparted among the general population regarding the simple measures of reducing dust mites such as washing bedding and nightclothes in hot water, encasing mattress and pillow in dust mite-proof covers, using washable blinds or curtains, and regularly checking air conditioning units for contamination and pest control [11].

The prevalence of allergic conjunctivitis, allergic dermatitis, and eczema were $40.8 \%, 34.9 \%$, and $14.9 \%$, respectively. The majority of the students had multiple coexistent allergies, allergic conjunctivitis coexistent with rhinitis being the most prevalent. The prevalence of allergic rhinoconjunctivitis in the present study was about $21 \%$; another study from Bangkok reported a prevalence rate of $26 \%$ for allergic rhinoconjunctivitis [12]. The prevalence of eczema among undergraduate students was $15 \%$, in comparison to $9.4 \%$ reported in the study from Bangkok, and $12.8 \%$ from Lebanon $[12,13]$. The highest prevalence rate of cutaneous allergy reported from the Middle East was 35.8\% in Tehran [14].

Shahar and Lorber from Israel reported prevalence rates of $7 \%, 6 \%$, and $7 \%$ for food allergy, drug allergy, and skin allergy, respectively [15]. In the present study the commonest food allergy was to sea food (crab) followed by nuts, while Al-Hammadi et al. from Al-Ain, UAE, had reported eggs, fruits, and fish as the main allergies in their study [4]. A report from Taiwan documented that protein-rich and fat-rich foods of animal origin were associated with a higher prevalence of allergies among the teenagers [16]. The most frequently reported drug allergies were to antibiotics, particularly to penicillin group. Allergic drug reactions have been reported to cause the highest number of documented deaths from anaphylaxis each year [17]. Hence it is critical for individuals with allergies to identify them and to avoid foods and drugs that may cause allergic reactions.

Family history of allergies was strongly associated with occurrence of allergic conjunctivitis and allergic dermatitis supporting previous publications on allergies from the United Arab Emirates $[5,10]$. This finding may be suggestive of a probable genetic influence on the development of allergies among the students. However in the present study we did not observe any association between the allergies and nationality of the student.

The effect of allergies on an individual's quality of life and the extent to which it may restrict daily activities are often ignored. Our study revealed that the allergies had restricted 
the daily activities of the students. Early identification of the allergens and avoiding them is the primary measure to reduce the occurrence of allergies. Educating and creating awareness regarding the allergic and respiratory diseases especially among the school students would help them identify the allergens and adopt precautionary measures.

Strength of the study is the high response rate of the students, inclusion of adolescents unlike children in most of the studies. The limitation of the study includes nongeneralizability of the findings to the entire population in the region due to the sample size in the present study and subjective nature of the responses (self-reported) may portray an overestimate of the true prevalence than a physician diagnosed allergy. In vitro IgE determination or in vivo skin prick test was not performed to identify the cause of allergies in these students.

\section{Conclusion}

Allergic conjunctivitis and allergic dermatitis were the frequent allergies reported. The study findings support the recent evidences of increasing prevalence of allergic diseases in the Middle Eastern region. The observations of the study highlight the need for future studies with larger sample to determine the true prevalence. Adequate preventive strategies such as creating awareness of allergic disease prevalence and its risk factors and treatment options can bring down mortality, morbidity, and disability caused by this public health problem.

\section{Appendix}

\section{Questionnaire}

Gender:

Age:

Nationality:

Length of stay in UAE

(1) In the past 12 months, have you had a problem with sneezing, or a runny, or a blocked nose when you did not have a cold or flu?

\section{Yes/No}

(2) In the past 12 months, have you ever had itchy-watery eyes?

$$
\text { Yes/No }
$$

(3) In the past 12 months, have you ever had an itchy rash?

$$
\text { Yes/No }
$$

(4) In the past 12 months, have you ever had eczema?

$$
\text { Yes/No }
$$

(5) In which of the past 12 months do you have these problems?

\section{January/February/March/April/ \\ May/June/July/August/September/October/ \\ November/December}

(6) Do any you have allergies to any of the following? Dust/Pollen/Food/ Drug/others

If yes, please specify

(7) Do any of your family members have any of the following allergies?

Allergy

Dermatitis

Yes $\mathrm{No}$

If yes,

Mother Father Sister Brother

Allergic rhinitis

Yes No

If yes,

Mother Father Sister Brother

Allergic conjunctivitis

Yes No

If yes,

Mother Father Sister Brother

(8) Has your allergies interfered with any of the following?

College attendance

Yes No

Exam performance

Yes No

Daily Activities

Yes No

Attending social gathering

Yes No

Extracurricular activities (sports, hobbies, exercise...)

Yes No

\section{Disclosure}

Presentation at congress: 6th and 7th October 2012, 4th EAPS Congress, Istanbul, Turkey.

\section{Conflict of Interests}

The authors declare that there is no conflict of interests regarding the publication of this paper. 


\section{Acknowledgment}

The authors acknowledge all the student participants for their cooperation.

\section{References}

[1] A. J. Woolcock, S. A. Bastiampillai, G. B. Marks, and V. A. Keena, "The burden of asthma in Australia," Medical Journal of Australia, vol. 175, no. 3, pp. 141-145, 2001.

[2] L. Bråbäck, A. Hjern, and F. Rasmussen, "Trends in asthma, allergic rhinitis and eczema among Swedish conscripts from farming and non-farming environments. A nationwide study over three decades," Clinical and Experimental Allergy, vol. 34, no. 1, pp. 38-43, 2004.

[3] L. Von Hertzen and T. Haahtela, "Disconnection of man and the soil: reason for the asthma and atopy epidemic?" Journal of Allergy and Clinical Immunology, vol. 117, no. 2, pp. 334-344, 2006.

[4] S. Al-Hammadi, F. Al-Maskari, and R. Bernsen, "Prevalence of food allergy among children in Al-Ain City, United Arab Emirates," International Archives of Allergy and Immunology, vol. 151, no. 4, pp. 336-342, 2010.

[5] S. Alsowaidi, A. Abdulle, R. Bernsen, and T. Zuberbier, "Allergic rhinitis and asthma: a large cross-sectional study in the United Arab Emirates," International Archives of Allergy and Immunology, vol. 153, no. 3, pp. 274-279, 2010.

[6] E. Von Mutius, "Is asthma really linked to atopy?" Clinical and Experimental Allergy, vol. 31, no. 11, pp. 1651-1652, 2001.

[7] A. Høst and S. Halken, "The role of allergy in childhood asthma," Allergy, vol. 55, no. 7, pp. 600-608, 2000.

[8] T.-N. Wang, W. Chiang, H.-I. Tseng et al., “The polymorphisms of Eotaxin 1 and CCR3 genes influence on serum IgE, Eotaxin levels and mild asthmatic children in Taiwan," Allergy, vol. 62, no. 10, pp. 1125-1130, 2007.

[9] A. Bener, W. Safa, S. Abdulhalik, and G.-G. Lestringant, "An analysis of skin prick test reactions in asthmatics in a hot climate and desert environment," Allergie et Immunologie, vol. 34, no. 8, pp. 281-286, 2002.

[10] S. Alsowaidi, A. Abdulle, A. Shehab, T. Zuberbier, and R. Bernsen, "Allergic rhinitis: prevalence and possible risk factors in a Gulf Arab population," Allergy, vol. 65, pp. 208-212, 2010.

[11] A. Sheikh and B. Hurwitz, "House dust mite avoidance measures for perennial allergic rhinitis: a systematic review of efficacy," British Journal of General Practice, vol. 53, no. 489, pp. 318-322, 2003.

[12] P. Vichyanond, S. Sunthornchart, V. Singhirannusorn, S. Ruangrat, S. Kaewsomboon, and N. Visitsunthorn, "Prevalence of asthma, allergic rhinitis and eczema among university students in Bangkok," Respiratory Medicine, vol. 96, no. 1, pp. 34-38, 2002.

[13] U. Musharrafieh, B. Al-Sahab, F. Zaitoun, M. A. El-Hajj, F. Ramadan, and H. Tamim, "Prevalence of asthma, allergic rhinitis and eczema among lebanese adolescents," Journal of Asthma, vol. 46, no. 4, pp. 382-387, 2009.

[14] G. B. Mirsaeid, S. H. Sharifi, K. Goodarzipoor et al., "The prevalence of Asthma among the students (7-18 years old) in Tehran during 2002-2003," Iranian Journal of Allergy, Asthma and Immunology, vol. 3, pp. 89-92, 2004.

[15] E. Shahar and M. Lorber, "Prevalence of self-reported allergic conditions in an adult population in Israel," Israel Medical Association Journal, vol. 3, no. 3, pp. 190-193, 2001.
[16] S.-L. Huang, K.-C. Lin, and W.-H. Pan, "Dietary factors associated with physician-diagnosed asthma and allergic rhinitis in teenagers: analyses of the first Nutrition and Health Survey in Taiwan," Clinical and Experimental Allergy, vol. 31, no. 2, pp. 259-264, 2001.

[17] J. S. Nugent, J. M. Quinn, C. M. McGrath, D. E. Hrncir, W. T. Boleman, and T. M. Freeman, "Determination of the incidence of sensitization after penicillin skin testing," Annals of Allergy, Asthma and Immunology, vol. 90, no. 4, pp. 398-403, 2003. 


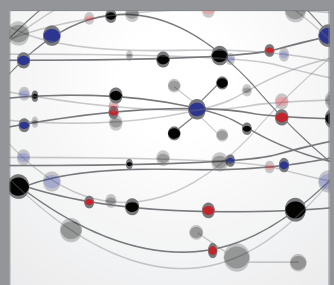

The Scientific World Journal
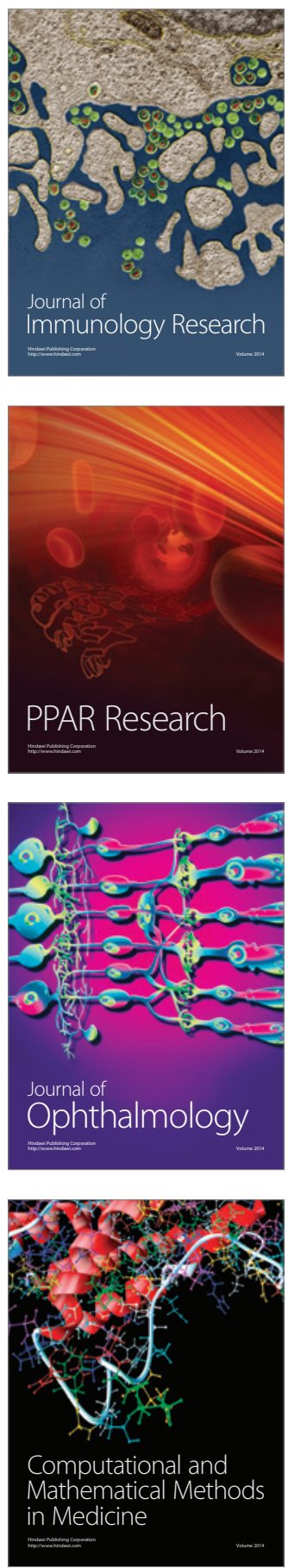

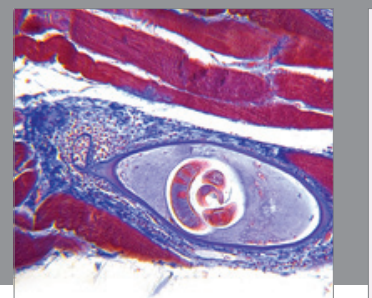

Gastroenterology

Research and Practice
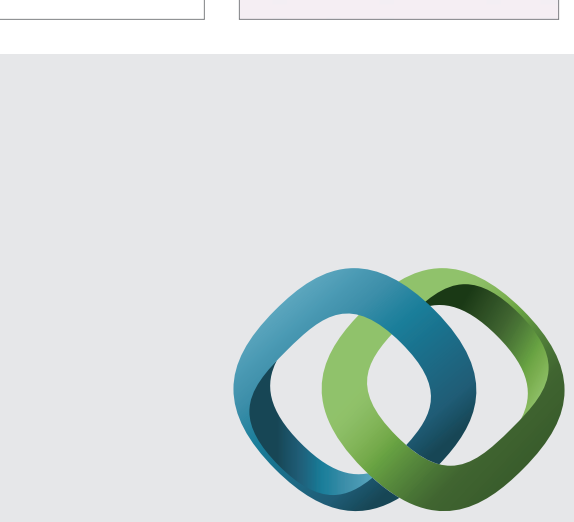

\section{Hindawi}

Submit your manuscripts at

http://www.hindawi.com
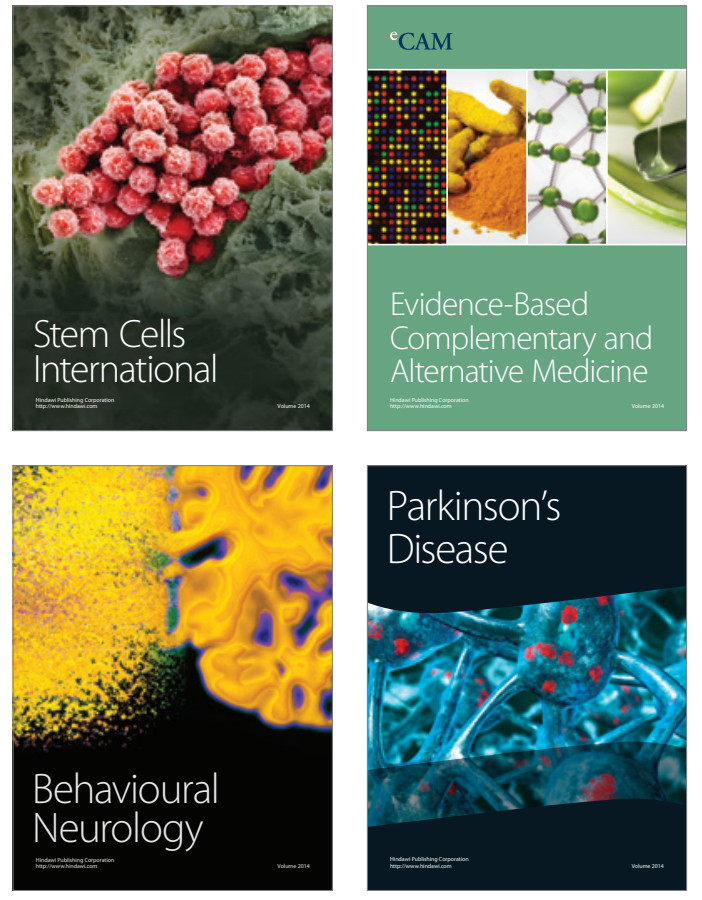
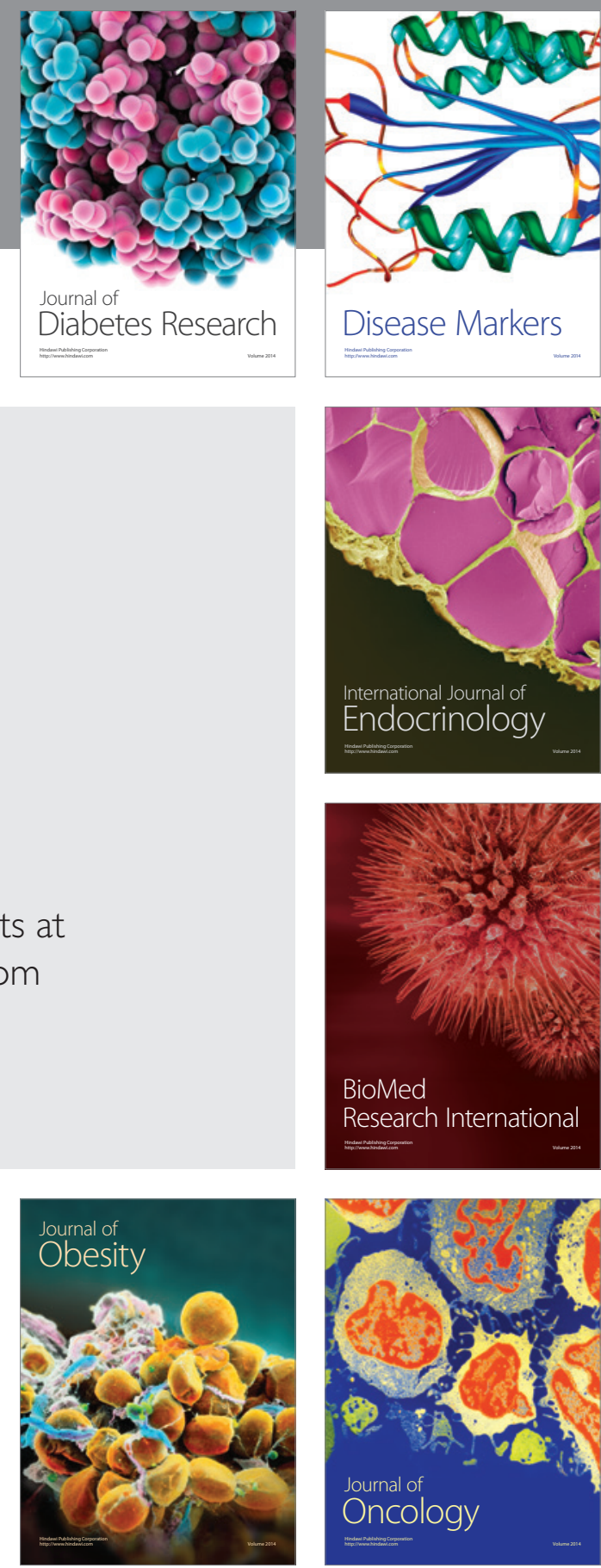

Disease Markers
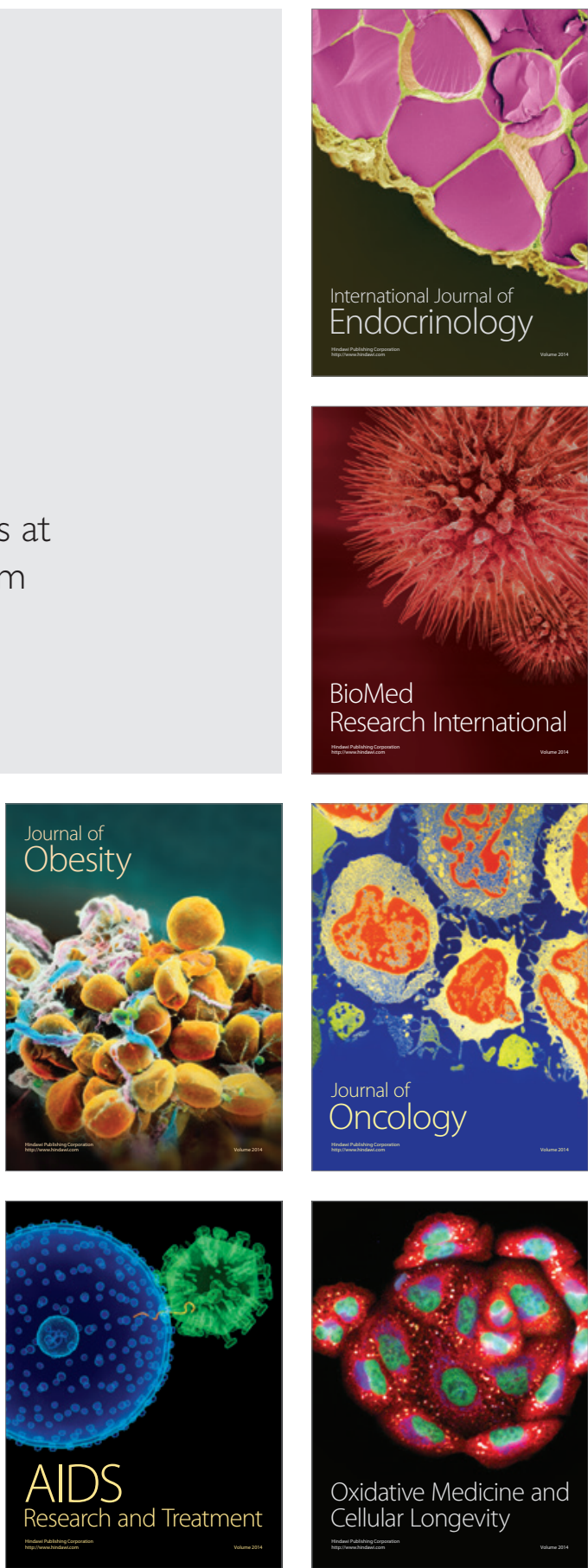